\title{
Variations in fresh fruit and vegetable quality by store type, urban-rural setting and neighbourhood deprivation in Scotland
}

\author{
Steven Cummins ${ }^{1, *}$, Dianna M Smith ${ }^{1}$, Mathew Taylor ${ }^{2}$, John Dawson ${ }^{2,3,4}$, \\ David Marshall ${ }^{2}$, Leigh Sparks ${ }^{3}$ and Annie S Anderson ${ }^{5}$ \\ 'Healthy Environments Research Programme, Department of Geography, Queen Mary, University of London, \\ Mile End Road, London E1 4NS, UK: ${ }^{2}$ Marketing Group, University of Edinburgh Business School, Edinburgh, \\ UK: ${ }^{3}$ Institute for Retail Studies University of Stirling, Stirling, UK: ${ }^{4}$ ESADE, Barcelona, Spain: ${ }^{5}$ Centre for Public \\ Health Nutrition Research, Ninewells Medical School, University of Dundee, Dundee, UK
}

Submitted 27 August 2008: Accepted 18 December 2008: First published online 26 February 2009

\begin{abstract}
Objective: Neighbourhood differences in access to fresh fruit and vegetables may explain social inequalities in diet. Investigations have focused on variations in cost and availability as barriers to the purchase and consumption of fresh produce; investigations of quality have been neglected. Here we investigate whether produce quality systematically varies by food store type, rural-urban location and neighbourhood deprivation in a selection of communities across Scotland.

Design: Cross-sectional survey of twelve fresh fruit and vegetable items in 288 food stores in ten communities across Scotland. Communities were selected to reflect a range of urban-rural settings and a food retail census was conducted in each location. The quality of twelve fruit and vegetable items within each food store was evaluated. Data from the Scottish Executive were used to characterise each small area by deprivation and urban-rural classification.

Setting: Scotland.

Results: Quality of fruit and vegetables within the surveyed stores was high. Medium-sized stores, stores in small town and rural areas, and stores in more affluent areas tended to have the highest-quality fresh fruit and vegetables. Stores where food is secondary, stores in urban settings and stores in more deprived areas tended have the lowest-quality fresh produce. Although differences in quality were not always statistically significant, patterns were consistent for the majority of fruit and vegetable items.

Conclusions: The study provides evidence that variations in food quality may plausibly be a micro-environmental mediating variable in food purchase and consumption and help partially explain neighbourhood differences in food consumption patterns.
\end{abstract}

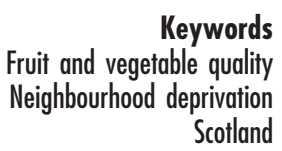

Consumption of a diet rich in fruit and vegetables may help prevent a range of diet-related health problems including CVD, cancer and stroke ${ }^{(1-3)}$. Health promotion efforts to improve intakes have traditionally concentrated on individually focused psychological and educational approaches, but these have met with limited success ${ }^{(4)}$. In recent years there has been a growing recognition that environmental, as well as individual, risk factors may influence food choice and thus nutrient intakes ${ }^{(5-7)}$.

Researchers have documented spatial variations in food consumption patterns, with neighbourhood deprivation independently predicting poor diet ${ }^{(8,9)}$. Differences in the characteristics of the food retail environment between deprived and affluent neighbourhoods have been hypothesised to explain these geographical inequalities. In the
USA, presence of a supermarket has been associated with an increase in consumption of fresh fruit and vegetables ${ }^{(10-12)}$ but the spatial patterning of these stores indicates that residents of minority and deprived neighbourhoods have poorer access to them ${ }^{(13-15)}$. In the UK, New Zealand and Australia the picture is more mixed, with cross-sectional studies reporting positive ${ }^{(8)}$ and negative ${ }^{(16-18)}$ associations between neighbourhood characteristics and fruit and vegetable consumption, and minimal differences in the price and availability of food between deprived and affluent neighbourhoods ${ }^{(19-21)}$. Intervention studies have also reported contrary findings, with improvements in local food grocery store provision having either having no effect ${ }^{(22,23)}$ or resulting in a small positive increase in individual fruit and vegetable intake ${ }^{(24)}$. 
However, many of these studies have simply quantified access to fruit and vegetables in terms of price, geographic distance to, or densities of, grocery stores selling fresh produce. There are few studies, and none in the UK, that have assessed the quality of fresh produce items within grocery stores. The quality of fresh fruit and vegetables on offer within stores may be a micro-environmental mediating variable that influences the purchasing behaviour of consumers while shopping - if an item is bruised, blemished, misshapen, pitted or moulding it may be perceived to be unappetising and poor value for money and thus is less likely to be purchased ${ }^{(25,26)}$. Such purchasing decisions may, in turn, negatively impact on overall diet quality by ensuring that fewer fruits and vegetables are purchased on shopping trips. One study in Detroit has found that mean quality of fruit and vegetables was lower in poor African-American neighbourhoods and higher in supermarkets ${ }^{(27)}$. Positive perceptions of fruit and vegetable quality were positively associated with a higher intake of these items ${ }^{(12)}$. Differences in fruit and vegetable quality may thus exist by store type and neighbourhood deprivation, which in turn may help explain neighbourhood variations in consumption patterns not explained by differences in price and availability. Here we investigate whether the quality of twelve commonly consumed fresh fruit and vegetable items varies by store type, urban-rural setting and neighbourhood deprivation in Scotland.

\section{Methods}

Ten study sites were purposively selected to represent the range of socio-environmental settings across Scotland on the basis of Scottish Executive's Urban-Rural Classification Scheme (SEUR) and the 2006 Scottish Index of Multiple Deprivation (SIMD). The final sample of study sites ensured coverage of the four main environmental settings in Scotland: island, rural, small town and urban. Sentinel sites were initially selected by stratifying all available data zones by the SEUR. Data zones are the core small-area statistical geography used in Scotland. There are currently 6505 data zones in Scotland with a mean population of 778 (range 500-1000).

Each of the 6505 data zones was grouped into three settings: (i) urban (SEUR 1 and 2); (ii) small town (SEUR 3 and 4); or (iii) rural (SEUR 5 and 6). Data zones within each of these settings were then divided into deciles of deprivation using the SIMD, an area-based measure of relative deprivation ${ }^{(28)}$. The SIMD is a publicly available continuous measure of compound social and material deprivation. Within the top and bottom deciles of each of the three settings, one data zone was randomly selected as the nucleus of the sentinel site. For each selected nucleus, additional data zones were added to build an overall sentinel site consisting of contiguous data zones that corresponded to the recognised local community.
Six sentinels were initially constructed: (i) urban affluent (Broughty Ferry, Dundee); (ii) urban deprived (Scotstoun/Drumchapel, Glasgow City); (iii) small town affluent (Ellon, Aberdeenshire); (iv) small town deprived (Kilbirnie, North Ayrshire); (v) rural affluent (Haddington, East Lothian); and (vi) rural deprived (Dornoch, The Highlands). However, this process did not select island communities (SEUR rural) and, as expected, the numbers of grocery stores available in some rural and small town settings were too small to conduct meaningful analyses. We therefore purposively selected four further sentinel sites to enhance coverage of the range of settings and boost small numbers of observations. Additional sites selected, on the basis of SEUR classifications, were Eilean Siar \& Orkney (islands), Cupar, Fife (small town affluent) and Inverness (urban mixed). In total 205 data zones were selected.

A comprehensive list of the street address and postcode of grocery stores selling food for home consumption (excluding takeaway/fast-food and coffee shop outlets) in the study sites was compiled. Data were initially obtained from industry (Institute of Grocery Distribution) and commercial (Marketscan and Catalist) sources. These data were later supplemented using company websites of the major multiple retailers (Tesco, Somerfield, Asda, Sainsbury and Morrisons), discounters (Aldi, Lidl) and freezer centres (Iceland, Farmfoods), online retail directories (Yell.com) and websites of symbol groups (Spar, Londis, Budgens, Costcutter). In addition, data from local authority registers (The Public Register of Food Premises) were also obtained. Data were combined, de-duplicated and cleaned on the basis of matching address and postcodes. Postcode validity was ascertained by joining the retail data with Ordnance Survey Code-Point information and identifying which postcodes could not be gridreferenced.

In total, 466 unique retail facilities were identified including both permanent and mobile/non-permanent locations such as farmers' market stalls. Of these locations, twenty-two had a missing, incorrect or incomplete postcode. Postcode errors were resolved by using the Royal Mail's online address/postcode checker ${ }^{(29)}$ and electronic searches of company websites and directories for thirteen of the twenty-two uncertain locations. The final dataset of geo-coded retail food sources for analysis included $98.1 \%$ ( $n$ 457) of the initially identified food retail facilities.

\section{Data on quality of fresh fruit and vegetable witbin stores}

Information on the quality of twelve commonly consumed fresh fruit and vegetables was obtained from instore visits by trained surveyors to all identified outlets in the food retail census. Data on the quality of produce items were collected as part of a broader project on healthy food price and availability. The quality indicator 
was included in the Healthy Eating Indicator Shopping Basket (HEISB) tool and consisted of a surveyor-reported visual assessment based on three-point Likert scale: $1=$ poor, $2=$ medium and $3=$ good, using the criteria outlined in Table 1. These criteria mirror the evaluations that consumers typically make when choosing to purchase fresh produce. Items included in the present study were apples, bananas, white grapes, oranges, potatoes, onions, carrots, broccoli, cucumber, round lettuce, red peppers and tomatoes. Data were collected in two phases: October/November 2005 to February/March 2006. Details on the rationale for the items included in HEISB have been reported elsewhere ${ }^{(30)}$.

\section{Analysis \\ Mean quality scores for individual fruit and vegetable items were calculated by shop type (small food superstore, $<3000$ sqft; medium food superstore, 3000-15000 sq ft; large food superstore, $>15000 \mathrm{sqft}$; specialist food store with a single function, e.g. greengrocer or butcher; and non- food store, e.g. where food is secondary such as a store selling alcohol), by SEUR category (island, rural, small town and urban) and by quintile of area deprivation. For area deprivation, each data zone in the study sites was assigned a score obtained from the $2006 \operatorname{SIMD}^{(28)}$. Data zones were then ranked and categorised into quintiles $(1=$ least deprived, $5=$ most deprived). Differences between cate- gories were assessed by ANOVA. Accepted level of sig- nificance was $P<0 \cdot 05$.}

\section{Results}

A total of $288(63.0 \%)$ stores stocked at least one fresh fruit or vegetable item. These stores were located in 177 of the 206 eligible data zones. Table 2 describes the distribution of these stores. All large and medium-sized stores stocked at least one fresh fruit or vegetable item, with $71 \cdot 8 \%$ of small stores selling fresh produce. The proportion of specialist and primarily non-food stores that stocked at least one fresh produce item was $36 \cdot 8 \%$ and $38.5 \%$, respectively. The proportion of stores selling these items by SEUR category was highest in island areas and lowest in urban areas. By deprivation the pattern was non-linear, with the proportion of stores selling fresh fruit and vegetables lowest in the most deprived areas (quintile 5) but highest in quintile 4.

Table 3 shows mean produce quality scores by store type. Quality was highest for apples $(P<0 \cdot 000)$, potatoes $(P=0 \cdot 001)$, onions $(P<0 \cdot 000)$ in medium stores; bananas in medium and specialist stores $(P=0.002)$; carrots in medium and large stores $(P=0.039)$; and red peppers in large stores $(P=0 \cdot 018)$. The same general pattern was observed for the remaining items with medium stores performing the best, although large stores had the highest quality scores for round lettuce, tomatoes and cucumber.
In all cases, stores where food is secondary had the lowest quality scores or did not stock particular items.

Mean produce quality scores by SEUR category are shown in Table 4. Quality scores were generally good for all items in all categories $(>2 \cdot 15)$. Four fruit and vegetable items had significant differences in quality by SEUR category: apples, potatoes, onions $(P<0 \cdot 000)$ and round lettuce $(P=0 \cdot 10)$, with rural or small town areas tending to have the highest-quality produce. For items with nonsignificant differences, rural and small town settings performed the best with the exception of broccoli (island). For nine of the twelve items the lowest mean quality scores were found in urban settings, with the exception of white grapes (rural), round lettuce and red peppers (island).

Table 5 shows mean produce quality scores by SIMD quintile of neighbourhood deprivation, with mean quality scores generally high in all quintiles $(>2 \cdot 08)$. Of all the twelve items, eight had the highest mean quality scores in SIMD quintile 2 and nine had the lowest mean quality scores in SIMD 4 or 5 . Significant differences were found for apples $(P=0 \cdot 016)$, potatoes $(P=0 \cdot 007)$ and onions $(P=0 \cdot 001)$, with highest mean quality scores found in SIMD quintile 2 and the lowest in SIMD quintile 5.

\section{Discussion}

Previous research undertaken in the UK has suggested that there are minimal differences in food price and availability between richer and poor neighbourhoods ${ }^{(16,19,31)}$ and as such these environmental factors may not explain geographical inequalities in diet and related diseases. However, the data presented here suggest that the quality of fresh fruit and vegetables within food stores differs by store type, urban-rural context and by neighbourhood deprivation. Overall the quality of fruit and vegetables within the surveyed stores was high. In general, medium-sized stores, stores in small town and rural areas, and stores in more affluent areas tended to have the highest-quality fresh fruit and vegetables on offer. Conversely, stores where food is secondary (nonfood), stores in urban settings and stores in less well-off areas tended have the lowest-quality fresh fruit and vegetables on offer. Although not all differences in quality were statistically significant, the patterns were consistent for the majority of the twelve fruit and vegetable items.

These data suggest a possible role for relative quality of fruit and vegetables as a micro-environmental variable which may mediate individual purchasing behaviour. It may be that although the aggregate cost and availability of individual food items does not vary by neighbourhood the quality of items sold does, with quality influenced by the type of store from which food is sold, whether the store is located in an urban or rural neighbourhood and how deprived that neighbourhood is. The patterns observed here build on earlier findings that fruit and 
Table 1 Description of fruit and vegetables for use in quality rating

Apples - loose eating

High/good: good strong intense bright red/green colour, no blemishes, bruises or marks, firm product, tight skin

Medium/acceptable: good red/green colour for variety, occasional blemish, perhaps a few marks, no bruises, firm product, looks good

Low/poor: weak red/green colour, marks, blemishes, bruised, blackened, soft, wrinkled/wilted skin, looks like it should be eaten immediately

Bananas - medium loose

High/good: strong green/yellow colour, no black marks, blemishes or bruises, product firm

Medium/acceptable: predominantly yellow/green stalk, occasional blemish, perhaps a few marks, no bruises, firm product, looks good Low/poor: brown marks on skin, blackening, wizened stalk, other blemishes, product feels soft, looks like it should be eaten immediately or used for cooking

Grapes (white) - bunch

High/good: bright green/white colour, well formed grapes, no deformed or wizened fruit, full stalks, no blemishes or moulds, fruit feels firm, looks succulent

Medium/acceptable: green/white colour, full bunch of grapes, one or two deformed/wizened grapes, occasional blemish/mould, firm fruit, tight skin

Low/poor: dull green/white colour, grapes look wizened/dried out, blemishes, moulds on some grapes, feel soft, some juice loss, loose grapes off stalk, soft to touch, some blackening

Oranges - medium loose

High/good: good strong intense bright orange colour, no blemishes, defects or marks, good shape for variety, smooth skin

Medium/acceptable: good orange colour for variety, occasional blemish, defect or mark, smooth skin, no wrinkling or drying, fruit firm

Low/poor: dull orange colour, skin dried and wrinkled, fruit soft, bruising, breaks in skin, juice leakage

Potatoes - white loose

High/good: no bruised or marked potatoes, firm product, no broken skin

Medium/acceptable: still firm product but not 'rubbery' feel, perhaps a few marks, no bruises

Low/poor: colour deterioration, produce feels soft, rubbery, dried out, skin wrinkled, evidence of product deterioration, sprouting

Onions - loose medium brown

High/good: bright, good colour, no blemishes, bruises or marks, firm product, skin intact

Medium/acceptable: occasional blemish, perhaps a few marks, no bruises, firm to touch

Low/poor: marks, blemishes/moulds, bruised, brown/black blotches, defects, greening of fleshy scales, leathery skin, soft to touch, product dried out

Carrots - medium loose

High/good: good bright orange colour, uniform size, straight products, firm, no splits or cracks

Medium/acceptable: good colour, reasonably straight, tolerable size variation, occasional marks but no browning

Low/poor: weak/dull colour, browning on vegetable, product not firm, rubbery feel (bends), wrinkled, hairy skin, drying out, sprouting

Broccoli - loose

High/good: good dark green colour, uniform size of head, firm, no mechanical damage or marks

Medium/acceptable: good green colour, fairly consistent size, occasional marks but product is firm, no colour change in the head (slight purple tinge is acceptable) or dried out stalks

Low/poor: yellow/black colour, stalk dried out, flaccid product, rubbery feel, evidence of damage or marks

Round lettuce - single

High/good: good bright light green colour, round head, crisp turgid feel/appearance, clean, no blemishes or browning of leaves

Medium/acceptable: light green colour, no browning, occasional blemish or dirt

Low/poor: weak colour, product looks 'flaccid', leaves not firm, water loss, browning on leaves, soil and mud on product (not clean), evidence of slugs, insect damage, spotting, brown stain

Red peppers - loose

High/good: good strong intense bright red colour, uniform shape and size, firm, free from cracks, decay, mould and fungi, clean, no blemishes, bruises or marks, firm crisp product, tight skin

Medium/acceptable: good red colour, mixed sizes, occasional blemish, no bruises or soft marks, firm product

Low/poor: soft product, brown marks, blemishes, moulds, wrinkled/wilted skin, product drying out

Tomatoes - loose standard medium

High/good: bright green/red colour, consistently sized products, no blemishes, bruises or abrasions, firm turgid product, shiny skin, no abrasions

Medium/acceptable: shiny red colour (90\%) for variety, no bruising, slight size variation, firm product, occasional blemish, perhaps a few marks, no bruises

Low/poor: dull red colour, marks, blemishes, bruised, product feels soft, skin not turgid but wrinkled/wilted

Cucumber - single whole

High/good: good dark green colour, uniform size, rigid and straight products, no pitted or wrinkled products i.e. pinched ends, no blemishes or marks

Medium/acceptable: dark green colour, fairly straight, tolerable size variation, occasional marks, but no browning or skin damage/ lacerations

Low/poor: weak colour, yellowing, water soaked areas of flesh from bruising, surface pitting, rubbery feel (bends), wrinkled, drying out, moulding

Scores assigned: low/poor $=1 ;$ medium/acceptable $=2 ;$ high $/$ good $=3$. 
vegetable quality is patterned by neighbourhood deprivation and by shop type ${ }^{(12,27)}$. For example, the findings reported here mirror those from an earlier study in Chicago $^{(32)}$ which found that 'independent' and 'liquor' stores in an urban area tended to stock the poorest-quality fresh produce. Analogous shops in the present study are 'small' and 'non-food' (where food is secondary) stores.

Factors influencing quality in Scotland might include: the quality of items purchased from wholesale markets; travel time from wholesale to retail premises (ripening and deterioration); food storage conditions in-store and in-transit; and volume turnover of food items. These in turn may depend on deprivation, rural-urban location and store type. To lessen variations in quality, Scottish retailers and wholesalers may need to improve storage

Table 2 Description of stores in the sample by store type, SEUR category and area deprivation, Scotland, 2005-6

\begin{tabular}{lrrr}
\hline & $\begin{array}{c}\text { All } \\
\text { stores }\end{array}$ & $\begin{array}{c}\text { Stores selling at least one fresh } \\
\text { fruit or vegetable item }\end{array}$ \\
\cline { 2 - 4 } & $n$ & $n$ & $\%$ \\
\hline Store type & & & \\
$\quad$ Large & 13 & 13 & $100 \cdot 0$ \\
Medium & 29 & 29 & $100 \cdot 0$ \\
Small & 266 & 191 & $71 \cdot 8$ \\
Specialist & 136 & 50 & $36 \cdot 8$ \\
Non-food & 13 & 5 & $38 \cdot 5$ \\
SEUR category & & & \\
Island & 100 & 80 & $80 \cdot 0$ \\
Rural & 81 & 53 & $65 \cdot 4$ \\
Small town & 54 & 32 & $59 \cdot 3$ \\
Urban & 222 & 123 & $55 \cdot 4$ \\
SIMD quintile & & & \\
1 (least deprived) & 66 & 40 & $60 \cdot 6$ \\
2 & 112 & 61 & $54 \cdot 5$ \\
3 & 101 & 77 & $76 \cdot 2$ \\
4 & 65 & 50 & $76 \cdot 9$ \\
5 (most deprived) & 113 & 60 & $53 \cdot 1$ \\
\hline
\end{tabular}

SEUR, Scottish Executive's Urban-Rural Classification Scheme; SIMD, 2006 Scottish Index of Multiple Deprivation. conditions allied with better marketing to encourage faster turnover of perishable goods. Finally, consumers, particularly those on low incomes, seek value for money. If increases in consumption are to be achieved, efforts to improve quality may in turn enhance perceptions of value and retail store reputation, providing a greater incentive to purchase and consume fresh fruit and vegetables from local outlets.

The study outlined here has certain limitations. The three-point Likert scale for assessing fruit and vegetable quality may not have been sufficiently sensitive to capture the full range of variation in item quality, resulting in higher than expected mean quality scores. The scale was a subjective rather than an objective measure although clear guidance on how to rate fruit and vegetable items was given. We were unable to examine inter-rater reliability as only one observer was sent into each store. The study was cross-sectional and ecological in design and does not link fruit and vegetable quality to individual purchasing or consumption behaviours. A snap-shot study such as this assumes that quality is stable over time when in fact it may vary due to other external factors such as wholesale supply. In this context, the study is best viewed as hypothesis generating rather than confirmatory. Further studies that explicitly investigate the influence of food quality in grocery stores on individual purchasing and consumption patterns are required.

The role of food quality, as opposed to price and availability, has yet to be fully investigated in the study of environmental determinants of diet. Although the present study only allows speculation on the possible influence of the patterns reported here, these data suggest that the quality of fruit and vegetable items may be worth investigating as a plausible micro-environmental determinant of purchasing and consumption behaviour. The study provides evidence that poorer-quality fruit and vegetable items are found in stores in urban settings, in stores

Table 3 Mean produce quality score of the twelve fresh fruit and vegetable items and number of stores selling the item by store type, Scotland, 2005-6

\begin{tabular}{|c|c|c|c|c|c|c|c|c|c|c|c|c|}
\hline \multirow[b]{3}{*}{ Item } & \multicolumn{10}{|c|}{ Store type* } & & \\
\hline & \multicolumn{2}{|c|}{ Large } & \multicolumn{2}{|c|}{ Medium } & \multicolumn{2}{|c|}{ Small } & \multicolumn{2}{|c|}{ Specialist } & \multicolumn{2}{|c|}{ Non-food } & \multicolumn{2}{|c|}{ ANOVA } \\
\hline & Score & $n$ & Score & $n$ & Score & $n$ & Score & $\bar{n}$ & Score & $\bar{n}$ & $F$ & $P$ \\
\hline Apples & $2 \cdot 69$ & 13 & $2 \cdot 93$ & 29 & $2 \cdot 49$ & 162 & $2 \cdot 76$ & 29 & $1 \cdot 50$ & 2 & $5 \cdot 542$ & 0.000 \\
\hline Bananas & 2.54 & 13 & $2 \cdot 71$ & 28 & $2 \cdot 32$ & 148 & $2 \cdot 71$ & 21 & $1 \cdot 75$ & 4 & $4 \cdot 310$ & 0.002 \\
\hline White grapes & $2 \cdot 85$ & 13 & $2 \cdot 88$ & 26 & $2 \cdot 64$ & 73 & $2 \cdot 69$ & 16 & - & & $1 \cdot 718$ & $0 \cdot 161$ \\
\hline Oranges & $2 \cdot 67$ & 12 & $2 \cdot 81$ & 26 & $2 \cdot 46$ & 142 & $2 \cdot 50$ & 28 & $2 \cdot 00$ & 1 & $2 \cdot 182$ & 0.072 \\
\hline Potatoes & $2 \cdot 62$ & 13 & $2 \cdot 85$ & 26 & $2 \cdot 60$ & 149 & $2 \cdot 83$ & 36 & $1 \cdot 67$ & 3 & $4 \cdot 661$ & 0.001 \\
\hline Onions & $2 \cdot 64$ & 11 & $2 \cdot 70$ & 27 & $2 \cdot 29$ & 168 & $2 \cdot 65$ & 40 & $1 \cdot 75$ & 4 & $6 \cdot 294$ & 0.000 \\
\hline Carrots & 2.75 & 12 & $2 \cdot 75$ & 24 & $2 \cdot 45$ & 130 & $2 \cdot 68$ & 34 & - & & $2 \cdot 833$ & 0.039 \\
\hline Broccoli & $2 \cdot 77$ & 13 & $2 \cdot 74$ & 27 & $2 \cdot 60$ & 60 & $2 \cdot 83$ & 24 & - & & $1 \cdot 213$ & 0.308 \\
\hline Round lettuce & $2 \cdot 92$ & 12 & $2 \cdot 77$ & 22 & $2 \cdot 44$ & 79 & $2 \cdot 71$ & 14 & - & & $2 \cdot 906$ & 0.037 \\
\hline Red pepper & $2 \cdot 85$ & 13 & $2 \cdot 68$ & 22 & $2 \cdot 31$ & 70 & $2 \cdot 58$ & 19 & $2 \cdot 00$ & 1 & 3.503 & 0.018 \\
\hline Tomatoes & $2 \cdot 77$ & 13 & $2 \cdot 41$ & 29 & $2 \cdot 36$ & 138 & $2 \cdot 59$ & 34 & - & & 1.533 & $0 \cdot 194$ \\
\hline Cucumber & 2.92 & 12 & $2 \cdot 83$ & 24 & $2 \cdot 70$ & 79 & $2 \cdot 88$ & 16 & - & & $1 \cdot 236$ & 0.299 \\
\hline
\end{tabular}

*Large, $>15000 \mathrm{sq} \mathrm{ft}$; medium, 3000-15000 sq ft; small, <3000 sq ft; specialist, food store with a single function (e.g. greengrocer or butcher); non-food store, store where food is secondary (e.g. one selling alcohol). 
Table 4 Mean produce quality score of the twelve fresh fruit and vegetable items and number of stores selling the item by SEUR classification, Scotland, 2005-6

\begin{tabular}{|c|c|c|c|c|c|c|c|c|c|c|}
\hline \multirow[b]{3}{*}{ Item } & \multicolumn{8}{|c|}{ SEUR category } & & \\
\hline & \multicolumn{2}{|c|}{ Island } & \multicolumn{2}{|c|}{ Rural } & \multicolumn{2}{|c|}{ Small town } & \multicolumn{2}{|c|}{ Urban } & \multicolumn{2}{|c|}{ ANOVA } \\
\hline & Score & $n$ & Score & $n$ & Score & $n$ & Score & $n$ & $F$ & $P$ \\
\hline Apples & $2 \cdot 68$ & 71 & $2 \cdot 80$ & 44 & $2 \cdot 81$ & 27 & $2 \cdot 33$ & 93 & $8 \cdot 871$ & 0.000 \\
\hline Bananas & $2 \cdot 43$ & 65 & $2 \cdot 56$ & 36 & $2 \cdot 55$ & 20 & $2 \cdot 31$ & 93 & 1.459 & 0.227 \\
\hline White grapes & $2 \cdot 69$ & 35 & $2 \cdot 68$ & 28 & $2 \cdot 86$ & 14 & $2 \cdot 73$ & 51 & 0.436 & 0.727 \\
\hline Oranges & $2 \cdot 61$ & 67 & $2 \cdot 51$ & 43 & $2 \cdot 59$ & 22 & $2 \cdot 43$ & 77 & $1 \cdot 208$ & 0.308 \\
\hline Potatoes & $2 \cdot 78$ & 63 & $2 \cdot 97$ & 37 & $2 \cdot 86$ & 22 & $2 \cdot 42$ & 105 & $14 \cdot 234$ & 0.000 \\
\hline Onions & $2 \cdot 57$ & 69 & $2 \cdot 50$ & 48 & $2 \cdot 71$ & 28 & $2 \cdot 15$ & 105 & $10 \cdot 508$ & 0.000 \\
\hline Carrots & $2 \cdot 57$ & 65 & $2 \cdot 53$ & 45 & $2 \cdot 64$ & 22 & $2 \cdot 49$ & 74 & 0.385 & 0.764 \\
\hline Broccoli & $2 \cdot 83$ & 36 & $2 \cdot 75$ & 32 & $2 \cdot 71$ & 17 & $2 \cdot 51$ & 39 & $2 \cdot 296$ & 0.081 \\
\hline Round lettuce & $2 \cdot 34$ & 32 & $2 \cdot 84$ & 31 & $2 \cdot 81$ & 16 & $2 \cdot 48$ & 48 & 3.969 & 0.010 \\
\hline Red pepper & $2 \cdot 29$ & 38 & $2 \cdot 63$ & 30 & $2 \cdot 64$ & 14 & $2 \cdot 48$ & 42 & $1 \cdot 739$ & 0.163 \\
\hline Tomatoes & $2 \cdot 44$ & 57 & $2 \cdot 68$ & 41 & $2 \cdot 26$ & 27 & $2 \cdot 34$ & 90 & $2 \cdot 542$ & 0.057 \\
\hline Cucumber & $2 \cdot 85$ & 34 & $2 \cdot 86$ & 29 & $2 \cdot 76$ & 17 & $2 \cdot 65$ & 51 & 1.626 & 0.187 \\
\hline
\end{tabular}

SEUR, Scottish Executive's Urban-Rural Classification Scheme.

Table 5 Mean produce quality score of the twelve fresh fruit and vegetable items and number of stores selling the item by area deprivation, Scotland, 2005-6

\begin{tabular}{|c|c|c|c|c|c|c|c|c|c|c|c|c|}
\hline \multirow[b]{3}{*}{ Item } & \multicolumn{10}{|c|}{ SIMD quintile* } & & \\
\hline & \multicolumn{2}{|c|}{1} & \multicolumn{2}{|c|}{2} & \multicolumn{2}{|c|}{3} & \multicolumn{2}{|c|}{4} & \multicolumn{2}{|c|}{5} & \multicolumn{2}{|c|}{ ANOVA } \\
\hline & Score & $n$ & Score & $n$ & Score & $n$ & Score & $n$ & Score & $n$ & $F$ & $P$ \\
\hline Apples & $2 \cdot 69$ & 35 & $2 \cdot 81$ & 52 & $2 \cdot 50$ & 58 & $2 \cdot 48$ & 46 & $2 \cdot 43$ & 44 & $3 \cdot 117$ & 0.016 \\
\hline Bananas & $2 \cdot 67$ & 30 & $2 \cdot 55$ & 44 & $2 \cdot 21$ & 56 & $2 \cdot 40$ & 40 & $2 \cdot 36$ & 44 & $2 \cdot 714$ & 0.031 \\
\hline White grapes & $2 \cdot 68$ & 22 & $2 \cdot 71$ & 28 & $2 \cdot 69$ & 39 & $2 \cdot 85$ & 13 & $2 \cdot 73$ & 26 & $0 \cdot 249$ & $0 \cdot 910$ \\
\hline Oranges & $2 \cdot 57$ & 28 & $2 \cdot 63$ & 52 & $2 \cdot 46$ & 54 & $2 \cdot 41$ & 41 & $2 \cdot 53$ & 34 & 0.949 & 0.437 \\
\hline Potatoes & $2 \cdot 74$ & 27 & $2 \cdot 80$ & 44 & $2 \cdot 74$ & 61 & $2 \cdot 60$ & 43 & $2 \cdot 42$ & 52 & $3 \cdot 628$ & 0.007 \\
\hline Onions & $2 \cdot 55$ & 33 & $2 \cdot 58$ & 53 & $2 \cdot 41$ & 68 & $2 \cdot 39$ & 46 & $2 \cdot 08$ & 50 & 4.969 & 0.001 \\
\hline Carrots & $2 \cdot 52$ & 31 & $2 \cdot 67$ & 45 & $2 \cdot 51$ & 61 & $2 \cdot 44$ & 36 & $2 \cdot 55$ & 33 & 0.692 & 0.598 \\
\hline Broccoli & $2 \cdot 63$ & 19 & $2 \cdot 71$ & 31 & $2 \cdot 76$ & 38 & $2 \cdot 55$ & 20 & $2 \cdot 75$ & 16 & 0.576 & 0.681 \\
\hline Round lettuce & $2 \cdot 73$ & 22 & $2 \cdot 67$ & 30 & $2 \cdot 61$ & 33 & $2 \cdot 39$ & 23 & $2 \cdot 42$ & 19 & $1 \cdot 081$ & 0.369 \\
\hline Red pepper & $2 \cdot 69$ & 16 & $2 \cdot 63$ & 32 & $2 \cdot 42$ & 36 & $2 \cdot 30$ & 23 & $2 \cdot 35$ & 17 & $1 \cdot 311$ & $0 \cdot 270$ \\
\hline Tomatoes & $2 \cdot 45$ & 33 & $2 \cdot 62$ & 47 & $2 \cdot 39$ & 54 & $2 \cdot 31$ & 39 & $2 \cdot 33$ & 42 & $1 \cdot 256$ & 0.289 \\
\hline Cucumber & $2 \cdot 61$ & 23 & $2 \cdot 87$ & 31 & $2 \cdot 80$ & 35 & $2 \cdot 69$ & 16 & $2 \cdot 77$ & 26 & $1 \cdot 013$ & 0.403 \\
\hline
\end{tabular}

SIMD, 2006 Scottish Index of Multiple Deprivation.

${ }^{*} 1=$ least deprived; $5=$ most deprived.

where food is secondary and in stores in more deprived neighbourhoods. These variations in food quality may help partially explain neighbourhood differences in food consumption patterns.

\section{Acknowledgements}

The present work was supported by the Food Standards Agency (Scotland) as part of the project 'Accessing Healthy Food: A National Assessment and Sentinel Mapping Study of Food Retailing in Scotland' (Ref: S04005). D.M.S. is supported by the award of the Philip Leverhulme Prize to S.C. S.C. is also supported by a NIHR Fellowship. There are no conflicts of interest. S.C. wrote the paper and directed analyses. D.M.S. conducted analyses and contributed to the writing. J.D., D.M., A.S.A. and L.S. contributed to paper drafting. M.T. directed and undertook the field work.

\section{References}

1. Joshipura KJ, Ascherio A, Manson JE, Stampfer MJ, Rimm EB, Speizer FE, Hennekens CH, Spiegelman D \& Willett WC (1999) Fruit and vegetable intake in relation to risk of ischemic stroke. JAMA 282, 1233-1239.

2. Joshipura KJ, Hu FB, Manson JE et al. (2001) The effect of fruit and vegetable intake on risk for coronary heart disease. Ann Intern Med 134, 1106-1114.

3. World Cancer Research Fund/American Institute of Cancer Research (2007) Food, Nutrition, Physical Activity and the Prevention of Cancer: A Global Perspective. Washington, DC: AICR.

4. Pomerleau J, Lock K, Knai C \& McKee M (2005) Interventions designed to increase adult fruit and vegetable intake can be effective: a systematic review of the literature. J Nutr 135, 2486-2495.

5. Booth SL, Sallis JF, Ritenbaugh C et al. (2001) Environmental and societal factors affect food choice and physical activity: rationale, influences, and leverage points. Nutr Rev 59, Suppl., S21-S39.

6. Story M, Kaphingst $\mathrm{K}$, Robinson-O'Brien $\mathrm{R} \&$ Glanz $\mathrm{K}$ (2008) Creating healthy food and eating environments: 
policy and environmental approaches. Annu Rev Public Health 29, 253-272.

7. Cummins S \& Macintyre S (2006) Food environments and obesity - neighbourhood or nation? Int J Epidemiol 35, 100-104.

8. Shohaimi S, Welch A, Bingham S, Luben R, Day N, Wareham N \& Khaw KT (2004) Residential area deprivation predicts fruit and vegetable consumption independently of individual educational level and occupational social class: a cross sectional population study in the Norfolk cohort of the European Prospective Investigation into Cancer (EPICNorfolk). J Epidemiol Community Health 58, 686-691.

9. Forsyth A, Macintyre S \& Anderson A (1994) Diets for disease? Intraurban variation in reported food consumption in Glasgow. Appetite 22, 259-274.

10. Rose D \& Richards R (2004) Food store access and household fruit and vegetable use among participants in the US Food Stamp Program. Public Health Nutr 7, 1081-1088.

11. Morland K, Wing S \& Diez Roux A (2002) The contextual effect of the local food environment on residents diets: The Atherosclerosis Risk in Communities Study. Am J Public Health 92, 1761-1767.

12. Zenk SN, Schulz AJ, Hollis-Neely T, Campbell RT, Holmes N, Watkins G, Nwankwo R \& Odoms-Young A (2005) Fruit and vegetable intake in African Americans - income and store characteristics. Am J Prev Med 29, 1-9.

13. Moore LV \& Roux AVD (2006) Associations of neighborhood characteristics with the location and type of food stores. Am J Public Health 96, 325-331.

14. Zenk SN, Schulz AJ, Israel BA, James SA, Bao SM \& Wilson ML (2005) Neighborhood racial composition, neighborhood poverty, and the spatial accessibility of supermarkets in metropolitan Detroit. Am J Public Health 95, 660-667.

15. Morland K, Wing S, Roux AD \& Poole C (2002) Neighborhood characteristics associated with the location of food stores and food service places. Am J Prev Med 22, 23-29.

16. Pearson T, Russell J, Campbell MJ \& Barker ME (2005) Do 'food deserts' influence fruit and vegetable consumption? A cross-sectional study. Appetite 45, 195-197.

17. Turrell G, Blakely T, Patterson C \& Oldenburg B (2004) A multilevel analysis of socioeconomic (small area) differences in household food purchasing behaviour. J Epidemiol Community Health 58, 208-215.

18. Pearce J, Hiscock R, Blakely T \& Witten K (2008) The contextual effects of neighbourhood access to supermarkets and convenience stores on individual fruit and vegetable consumption. I Epidemiol Community Health 62, 198-201.
19. Cummins S \& Macintyre S (2002) A systematic study of an urban foodscape: the price and availability of food in Greater Glasgow. Urban Studies 39, 2115-2130.

20. Winkler E, Turrell G \& Patterson C (2006) Does living in a disadvantaged area entail limited opportunities to purchase fresh fruit and vegetables in terms of price, availability, and variety? Findings from the Brisbane Food Study. Health Place 12, 741-748.

21. Pearce J, Witten K, Hiscock R \& Blakely T (2007) Are socially disadvantaged neighbourhoods deprived of health-related community resources? Int J Epidemiol 36, 348-355.

22. Cummins S, Petticrew M, Higgins C, Findlay A \& Sparks L (2005) Large scale food retailing as an intervention for diet and health: quasi-experimental evaluation of a natural experiment. J Epidemiol Community Health 59, 1035-1040.

23. Cummins S, Findlay A, Higgins C, Petticrew M, Sparks L \& Thomson H (2008) Reducing inequalities in health and diet: findings from a study on the impact of a food retail development. Environ Plann A 40, 402-422.

24. Wrigley N, Warm D \& Margetts B (2003) Deprivation, diet, and food-retail access: findings from the Leeds 'food deserts' study. Environ Plann A 35, 151-188.

25. Glanz K, Sallis JF, Saelens BE \& Frank LD (2005) Healthy nutrition environments: concepts and measures. Am J Health Promot 19, 330-333.

26. Jago R, Baranowski T \& Baranowski JC (2007) Fruit and vegetable availability: a micro environmental mediating variable? Public Health Nutr 10, 681-689.

27. Zenk SN, Schulz AJ, Israel BA, James SA, Bao SM \& Wilson ML (2006) Fruit and vegetable access differs by community racial composition and socioeconomic position in Detroit, Michigan. Ethn Dis 16, 275-280.

28. Scottish Executive (2006) Scottish Index of Multiple Deprivation 2006. http://www.scotland.gov.uk/Topics/ Statistics/SIMD/ (accessed August 2008).

29. Royal Mail (2008) Royal Mail Postcode Checker. http:// www.royalmail.com/portal/rm (accessed August 2008).

30. Anderson AS, Dewar J, Marshall D, Cummins S, Taylor M, Dawson J \& Sparks L (2007) The development of a healthy eating indicator shopping basket tool (HEISB) for use in food access studies - identification of key food items. Public Health Nutr 10, 1440-1447.

31. Cummins S \& Macintyre S (2002) 'Food deserts' - evidence and assumption in health policy making. BMJ 325, 436-438.

32. Block D \& Kouba J (2006) A comparison of the availability and affordability of a market basket in two communities in the Chicago area. Public Health Nutr 9, 837-845. 